NASA/CR-2003-212594

NEXT Ion Optics Simulation via ffx

\author{
Cody C. Farnell, John D. Williams, and Paul J. Wilbur
}

Colorado State University, Fort Collins, Colorado 
Since its founding, NASA has been dedicated to the advancement of aeronautics and space science. The NASA Scientific and Technical Information (STI) Program Office plays a key part in helping NASA maintain this important role.

The NASA STI Program Office is operated by Langley Research Center, the Lead Center for NASA's scientific and technical information. The NASA STI Program Office provides access to the NASA STI Database, the largest collection of aeronautical and space science STI in the world. The Program Office is also NASA's institutional mechanism for disseminating the results of its research and development activities. These results are published by NASA in the NASA STI Report Series, which includes the following report types:

- $\quad$ TECHNICAL PUBLICATION. Reports of completed research or a major significant phase of research that present the results of NASA programs and include extensive data or theoretical analysis. Includes compilations of significant scientific and technical data and information deemed to be of continuing reference value. NASA's counterpart of peerreviewed formal professional papers but has less stringent limitations on manuscript length and extent of graphic presentations.

- TECHNICAL MEMORANDUM. Scientific and technical findings that are preliminary or of specialized interest, e.g., quick release reports, working papers, and bibliographies that contain minimal annotation. Does not contain extensive analysis.

- CONTRACTOR REPORT. Scientific and technical findings by NASA-sponsored contractors and grantees.
- CONFERENCE PUBLICATION. Collected papers from scientific and technical conferences, symposia, seminars, or other meetings sponsored or cosponsored by NASA.

- SPECIAL PUBLICATION. Scientific, technical, or historical information from NASA programs, projects, and missions, often concerned with subjects having substantial public interest.

- TECHNICAL TRANSLATION. Englishlanguage translations of foreign scientific and technical material pertinent to NASA's mission.

Specialized services that complement the STI Program Office's diverse offerings include creating custom thesauri, building customized databases, organizing and publishing research results ... even providing videos.

For more information about the NASA STI Program Office, see the following:

- Access the NASA STI Program Home Page at http://www.sti.nasa.gov

- E-mail your question via the Internet to help@sti.nasa.gov

- Fax your question to the NASA Access Help Desk at 301-621-0134

- Telephone the NASA Access Help Desk at 301-621-0390

- Write to:

NASA Access Help Desk

NASA Center for AeroSpace Information 7121 Standard Drive

Hanover, MD 21076 
NASA/CR-2003-212594

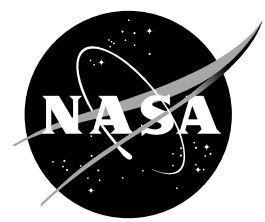

NEXT Ion Optics Simulation via ffx

Cody C. Farnell, John D. Williams, and Paul J. Wilbur

Colorado State University, Fort Collins, Colorado

Prepared for the

39th Joint Propulsion Conference and Exhibit

cosponsored by the AIAA, ASME, SAE, and ASEE

Huntsville, Alabama, July 20-23, 2003

Prepared under Grant NAG3-1801

National Aeronautics and

Space Administration

Glenn Research Center 


\section{Acknowledgments}

The authors wish to thank NASA Glenn for sponsoring this work.

This report contains preliminary

findings, subject to revision as analysis proceeds.

Available from

NASA Center for Aerospace Information 7121 Standard Drive

Hanover, MD 21076
National Technical Information Service 5285 Port Royal Road

Springfield, VA 22100

Available electronically at http:/ /gltrs.grc.nasa.gov 


\title{
NEXT ION OPTICS SIMULATION VIA ffx
}

\author{
Cody C. Farnell,* John D. Williams, $\dagger$ and Paul J. Wilbur $\ddagger$ \\ Colorado State University \\ Fort Collins, Colorado 80523
}

\begin{abstract}
$\underline{\text { ABSTRACT }}$
Simulations of the erosion processes for two proposed sets of ion thruster grids for the NEXT project are presented. Structural failure and electron backstreaming due to accel grid erosion are discussed as two possible failure mechanisms of these grid sets. The TAG grid set is shown to outperform the NSTAR grid set both in terms of margin against electron backstreaming and accel grid mass loss at the primary operating condition studied. An investigation into the possibility of reducing the accel grid voltage magnitude for the TAG grid set showed improved propellant throughput capability. Results of erosion simulations predicting propellant throughput capability for the TAG grid set are presented for a range of NEXT operating conditions.
\end{abstract}

\section{INTRODUCTION}

NASA's Evolutionary Xenon Thruster (NEXT) is being developed at Glenn Research Center as an advancement of the NSTAR thruster design heritage with significant increases in power and total impulse to meet the needs of more ambitious missions, such as those missions to the outer planets as well as sample-return missions. ${ }^{1}$ The NEXT thruster beam diameter is $40 \%$ greater than that of the NSTAR thruster, and this results in a beam area that is nearly doubled. Operating at higher grid voltages while maintaining current densities similar to those of NSTAR, the NEXT thruster is expected to provide over twice the propellant processing capability with only slight modifications to the discharge chamber, hollow cathode assemblies, and grid optics. Specifically, the NEXT thruster is being designed to a flight requirement of $270 \mathrm{~kg}$ of propellant throughput, which corresponds to a requirement for a ground-based demonstration of $405 \mathrm{~kg}$.

\footnotetext{
* AIAA Member, Graduate Research Assistant

+ AIAA Senior Member, Assistant Professor

\$ AIAA Senior Member, Professor
}

Sputter erosion of the downstream face and aperture barrel of the accel grid were identified as the two modes of grid failure that were most important in determining the lifetime of the NSTAR thruster optics. ${ }^{2}$ As an alternative to a change in grid material, which would presumably increase grid lifetime by reducing the sputter erosion rate, an increase in accel grid thickness was identified as a possible way to extend the life of the accel grid. By changing the grid design and not the grid material, the well developed fabrication and processing techniques of molybdenum grids used in the NSTAR program could also be used for the NEXT thruster.

The two grid sets proposed for the NEXT thruster are referred to in this paper as the NSTAR and TAG grid sets. The NSTAR optics have the same dimensions as those used in the NSTAR thruster with the exception of the larger grid diameter, while the TAG optics have a $50 \%$ thicker accel grid that is intended to increase the overall amount of grid material available to be sputtered, as well as to lower the accel grid voltage magnitude required to prevent electron backstreaming.

In order to investigate the possible advantages of an increase in accel grid thickness, a collaborative effort to model the NSTAR and TAG geometries was undertaken by groups at Colorado State University, the University of Michigan, and the Jet Propulsion Laboratory. The goal of this effort was to make a recommendation for the selection of the NSTAR or TAG grid geometries based on grid lifetime, as well as to advance the state of ion optics modeling.

\section{SIMULATION METHOD}

The ffx code analyzes a three-dimensional, rectangular volume with symmetry conditions applied on appropriate sides. For a hexagonal aperture layout, the code analyzes two, quarter-sized apertures. The mesh size for both the NSTAR and TAG grid geometries was approximately 32 by 56 by 232 cells, where each cell was nearly cubic in shape. Approximately 18,000 particles were sent through the volume during each ion 
beamlet simulation loop, which resulted in at least 10 macro particles per cell being injected into the volume at the upstream boundary.

Poisson's equation is solved using a combination of the multigrid method and the red-black Gauss-Seidel method with relaxation. Electron space charge is introduced using equations that describe the electron density at each mesh point according to individual mesh point potentials along with average values of the upstream or downstream ion densities.

Erosion due to charge exchange ion impingement was calculated according to the impacting ion's energy and angle of impingement. Grid material ejected from the surface was modeled using a cosine distribution.

The downstream distance used for these simulations was usually set to about $6 \mathrm{~mm}$ as a balance between keeping a simulation that both captured downstream charge exchange ion effects and had a reasonable simulation time. The position of the neutralization surface was checked in each case to make sure that there was sufficient distance between it and the downstream boundary to ensure that the boundary position was not affecting the simulation results. To obtain the desired experimentally measured impingement current results, the neutral density near the downstream boundary was adjusted to a slightly higher level if needed to yield the appropriate total charge exchange ion current.

The erosion time step was usually set to 400 hours, which implies that the grid geometry remains nearly constant over each 400-hour time step. Each erosion time step requires approximately 20 minutes to simulate, which includes the completion of about five ion beamlet loops that are required to adjust the beamlet shape according to the changing grid shape, as well as calculations of charge exchange ion production, tracking, and sputtered grid material re-deposition.

\section{NEXT INPUT VALUES}

Experimental data were used to obtain curve fits of various parameters for input into the $\mathrm{ffx}$ code. Parameters were generally a function of beam current rather than beam voltage. The accel grid impingement currents were found to be nearly the same for both the NSTAR and TAG geometries. The following curve fit gives the total accel grid impingement current $\left(\mathrm{J}_{\mathrm{A}}\right.$ in $m A$ ) for a given beam current $\left(J_{B}\right.$ in $\left.A\right)$.

$$
J_{A}=0.7071 \cdot J_{B}^{2}+1.7342 \cdot J_{B}
$$

Data from the TAG grid set were used to obtain a curve fit of flatness parameter (F) as a function of beam current $\left(J_{B}\right.$ in $\left.A\right)$. These flatness parameters were used to adjust both the beam and impingement current per aperture values to peak (thruster centerline) beam and impingement current per aperture values.

$$
F=0.0053 \cdot J_{B}^{2}+0.0317 \cdot J_{B}+0.5328
$$

The double-to-single current ratio was found to be nearly constant over all beam currents and beam voltages.

$$
\frac{J_{++}}{J_{+}}=-0.0009 \cdot J_{B}^{2}+0.0052 \cdot J_{B}+0.0355
$$

The beam current in the NEXT thruster varies from 1.20 to $3.52 \mathrm{~A}$. The corresponding values of the above parameters are summarized in Table 1 .

TABLE 1. Input parameter ranges.

\begin{tabular}{ccc|c}
$\mathrm{J}_{\mathrm{B}}$ & $\mathrm{A}$ & 1.2 & 3.52 \\
\hline $\mathrm{J}_{\mathrm{A}}$ & $\mathrm{mA}$ & 3.1 & 14.9 \\
$\mathrm{~J}_{\mathrm{A}} / \mathrm{J}_{\mathrm{B}}$ & $\%$ & 0.26 & 0.42 \\
$\mathrm{~F}$ & - & 0.58 & 0.71 \\
$\mathrm{~J}_{++} / \mathrm{J}_{+}$ & - & 0.040 & 0.043
\end{tabular}

In each particular case being simulated, the discharge chamber plasma potential was set $6 \mathrm{~V}$ higher than the beam voltage, and the screen grid potential was set 24 $\mathrm{V}$ lower than the beam voltage. In all cases, the downstream beam plasma potential was $22 \mathrm{~V}$ and the upstream and downstream electron temperatures were 6 and $1 \mathrm{eV}$, respectively. All other input parameters, such as the propellant flow rates, were taken directly from the NEXT throttle table at each particular operating condition.

\section{ACCEL GRID FAILURE MODES}

The two modes of accel grid failure that were examined were structural failure and failure due to electron backstreaming. Regarding structural failure, the end of life of the accel grid was selected to occur when $50 \%$ of the original accel grid mass had been eroded away. For electron backstreaming, the "least negative" potential along the beamlet centerline within the accel 
grid region was used along with the value of the downstream beam plasma potential to determine the voltage margin against electron backstreaming. The end of life due to electron backstreaming therefore occurred when the margin against backstreaming was less than zero volts. Structural failure is generally related to the erosion of the downstream face of the accel grid, while electron backstreaming tends to be related to the enlargement of the accel grid aperture diameter as a result of barrel erosion.

\section{RESULTS}

Impingement limit curves were generated for four operating points. The simulated beam voltages were $1800,1396,1021$, and $679 \mathrm{~V}$. The corresponding accel grid voltages were $-250,-220,-175$, and $-115 \mathrm{~V}$. Generally, beamlet currents over the entire grid area should be operated between the crossover and perveance limits to avoid energetic ions from the discharge chamber directly impinging upon the accel grid. ${ }^{4}$ The crossover limit (at relatively low beamlet current) occurs when ions entering the aperture crossover the beamlet centerline and impinge upon the downstream edge of the accel grid aperture on the opposite side of the aperture from which they started. The perveance limit (at relatively high beamlet current) occurs when ions entering the aperture accelerate directly downstream and impinge upon the accel grid on the same side of the aperture from which they started, usually on the upstream face. In each of the NEXT beam voltage cases, no crossover limit was predicted by the code. As the beamlet current was decreased, the discharge plasma sheath moved continuously upstream and ions entering the upstream surface were never over-focused through the accel grid apertures. The perveance limits that were identified at each of the NEXT operating points are compared in Fig. 1 as a function of beam voltage. The throttling table requirements are also shown on this figure and are seen to be well below the perveance limit beamlet currents. These results agree with the approach of the NSTAR and NEXT engine designs of maintaining low beam current densities (and low perveance conditions) in order to increase grid lifetime. ${ }^{3}$

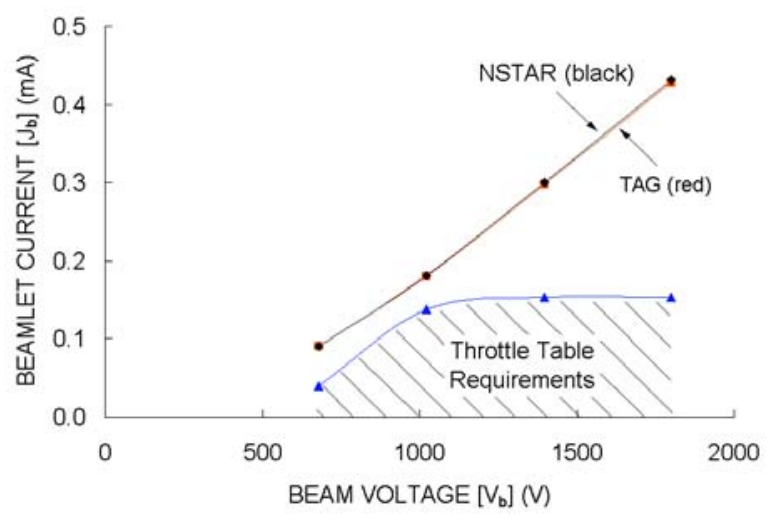

Fig. 1 Perveance limits as a function of beam voltage.

Figure 2 shows the margin against electron backstreaming as a function of beamlet current for each of the four beam voltage cases. For both the NSTAR and TAG geometries, the minimum margin against backstreaming tends to occur at the greatest beamlet current at each beam voltage. The eight minimum margins from Fig. 2 are plotted as a function of beam voltage in Fig. 3. The applied accel grid voltages were originally chosen to give a $50 \mathrm{~V}$ margin against backstreaming for the NSTAR grid geometry at each beam voltage. The ffx predicted margin was close to 50 $\mathrm{V}$ for the 679 and $1800 \mathrm{~V}$ beam voltages, while the predicted margins were greater than $50 \mathrm{~V}$ for the 1021 and $1396 \mathrm{~V}$ beam voltages. The difference in backstreaming margin between the NSTAR and TAG optics ranged from $14 \mathrm{~V}$ at a beam voltage of $679 \mathrm{~V}$, to $35 \mathrm{~V}$ at a beam voltage of $1800 \mathrm{~V}$. These backstreaming margin differences are slightly larger than those seen in the experimental data, where the backstreaming margin difference varied from 8 to $19 \mathrm{~V}$ over the same beam voltage range. ${ }^{3}$

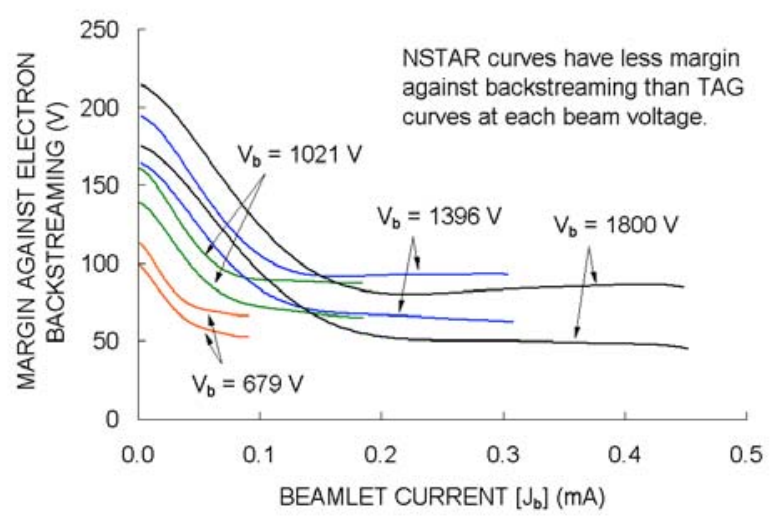

Fig. 2 Margin against electron backstreaming as a function of beamlet current and beam voltage. 


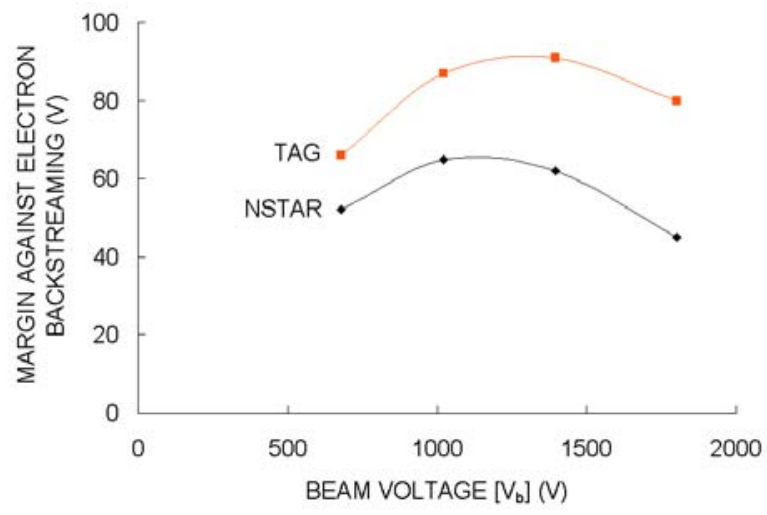

Fig. 3 Overall margin against electron backstreaming as a function of beam voltage.

The operating condition that was investigated most thoroughly in this study corresponded to a total beam current of $3.52 \mathrm{~A}$ and a beam voltage of $1800 \mathrm{~V}$. Here the average beamlet current was calculated to be 0.118 $\mathrm{mA}$ and the peak (thruster centerline) beamlet current was calculated to be $0.167 \mathrm{~mA}$ using a flatness parameter of 0.71 . Figure 4 compares the margin against electron backstreaming as a function of total propellant throughput for the NSTAR and TAG geometries at the average and peak beamlet currents. Figure 5 compares the accel grid percent mass loss as a function of propellant throughput for the same four cases. Through comparisons between these two figures, it can be concluded that in all four cases, the end of life of both grid sets was determined by excessive accel grid mass loss rather than by electron backstreaming. Additionally, the greater beamlet current aperture for both grid sets limited the propellant throughput capability, with the NSTAR grid set having a propellant throughput of $435 \mathrm{~kg}$ and the TAG grid set a propellant throughput of $625 \mathrm{~kg}$.

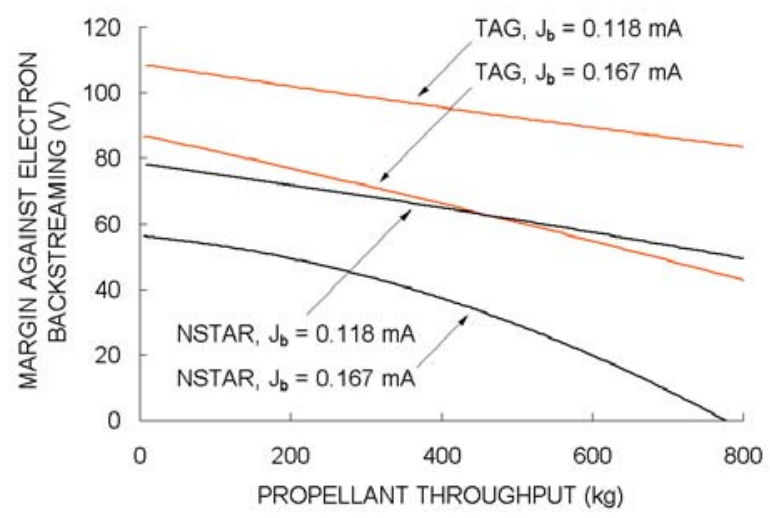

Fig. 4 Backstreaming margin of apertures operating at $\mathrm{J}_{\mathrm{B}}=3.52 \mathrm{~A}, \mathrm{~V}_{\mathrm{b}}=1800 \mathrm{~V}$, and $\mathrm{V}_{\mathrm{a}}=-250 \mathrm{~V}$.

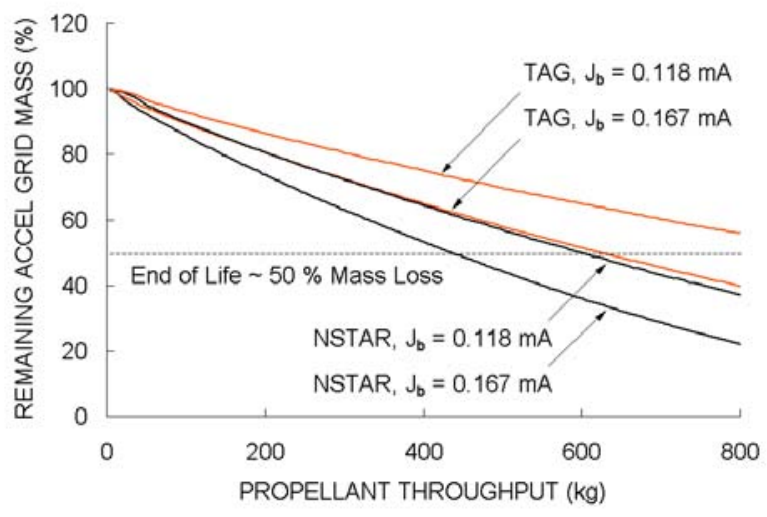

Fig. 5 Accel grid mass loss of apertures operating at $\mathrm{J}_{\mathrm{B}}$ $=3.52 \mathrm{~A}, \mathrm{~V}_{\mathrm{b}}=1800 \mathrm{~V}$, and $\mathrm{V}_{\mathrm{a}}=-250 \mathrm{~V}$.

Figure 6 shows the depth of erosion through the accel grid thickness as a function of propellant throughput for the NSTAR and TAG grid sets at a beamlet current of $0.167 \mathrm{~mA}$ and a beam voltage of $1800 \mathrm{~V}$. Figure 7 shows cross sections of the accel grid for the same operating condition at the same propellant throughput steps. It can be concluded from these figures that the erosion of the downstream surface is much more pronounced than the erosion of the accel grid barrel. This is a result of the ion beamlet being well focused at this condition, and is related to the beamlet current, $0.167 \mathrm{~mA}$, being much less than the perveance limit beamlet current, $0.45 \mathrm{~mA}$, at this beam voltage. Barrel erosion is more predominant when operating closer to the perveance limit, where the beamlet diameter is larger and charge exchange ions generated in the region between the grids are more likely to be focused into the accel grid barrel. Also noticeable in these figures is that pit erosion, which occurs on the downstream face of the accel grid between any three apertures, was not significantly more severe (deeper) than groove erosion, which occurs along the lines between pit locations. 


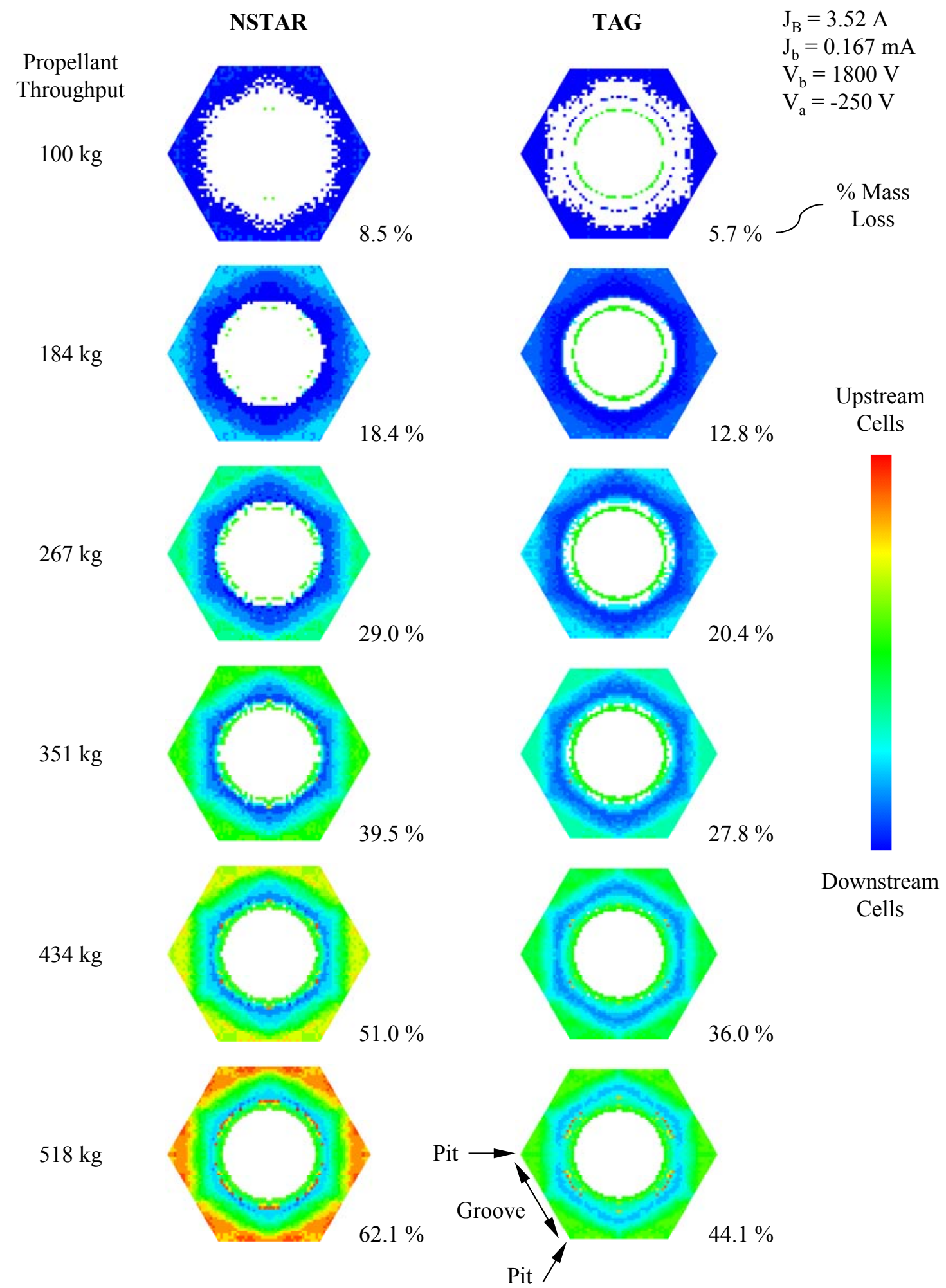

Fig. 6 Downstream face view of accel grid erosion depth (colored cells have been eroded away). 
$\mathrm{J}_{\mathrm{B}}=3.52 \mathrm{~A}$

$\mathrm{J}_{\mathrm{b}}=0.167 \mathrm{~mA}$

$\mathrm{V}_{\mathrm{b}}=1800 \mathrm{~V}$

$\mathrm{V}_{\mathrm{a}}=-250 \mathrm{~V}$

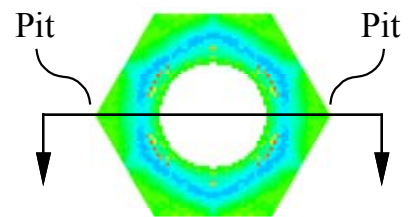

NSTAR

TAG

Propellant

Throughput

(

$100 \mathrm{~kg}$

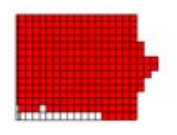

$\%$ Mass Loss
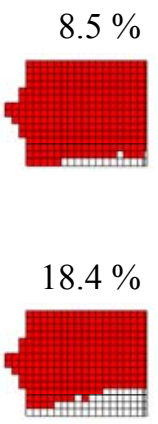

$267 \mathrm{~kg}$
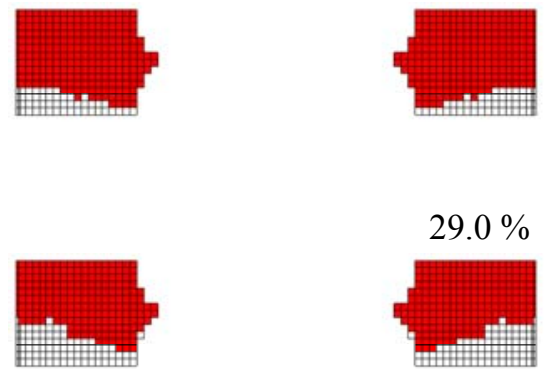

$39.5 \%$

$351 \mathrm{~kg}$
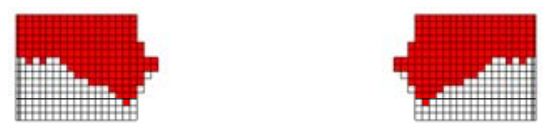

$51.0 \%$

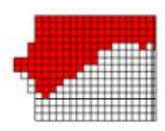

$62.1 \%$

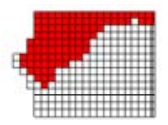

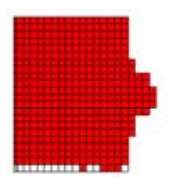
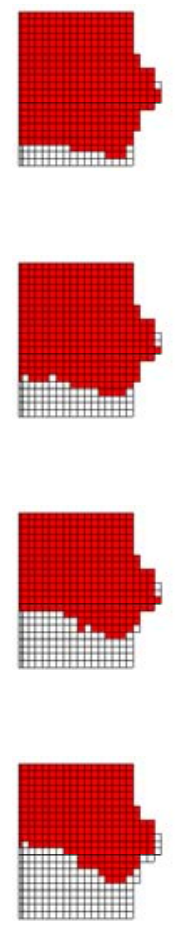

\% Mass Loss

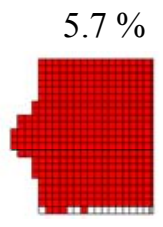

$12.8 \%$

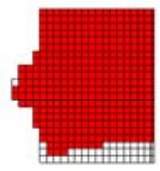

$20.4 \%$

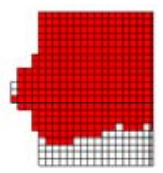

$27.8 \%$

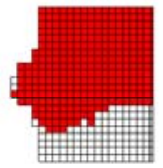

$36.0 \%$

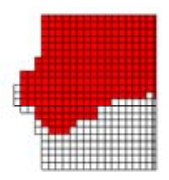

$44.1 \%$
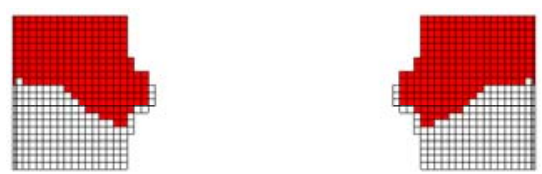

Fig. 7 Accel grid cross sections (uncolored cells have been eroded away). 
The TAG geometry has a greater than $50 \mathrm{~V}$ margin against electron backstreaming at the $3.52 \mathrm{~A}$ beam current, $1800 \mathrm{~V}$ beam voltage condition. A reduction in the magnitude of the accel grid voltage was investigated as a way to increase the accel grid lifetime by reducing the energy at which charge exchange ions strike the accel grid. Figure 8 compares the margin against backstreaming as a function of propellant throughput for the TAG geometry at accel grid voltages of -250 , -225 , and $-200 \mathrm{~V}$. Figure 9 shows the corresponding accel grid mass that remains as a function of propellant throughput for the same cases. Also shown in these two figures for reference is the NSTAR grid erosion data at an accel grid voltage of $-250 \mathrm{~V}$. In this case, the change in margin against backstreaming is greater than the change in rate of mass loss from the accel grid. However, structural failure of the accel grid due to 50 $\%$ mass loss is still predicted to determine the end of life before the onset of electron backstreaming. The propellant throughput capability of the TAG grid set was seen to increase from $625 \mathrm{~kg}$ at an accel grid voltage of $-250 \mathrm{~V}$ to $805 \mathrm{~kg}$ at an accel grid voltage of $-200 \mathrm{~V}$.

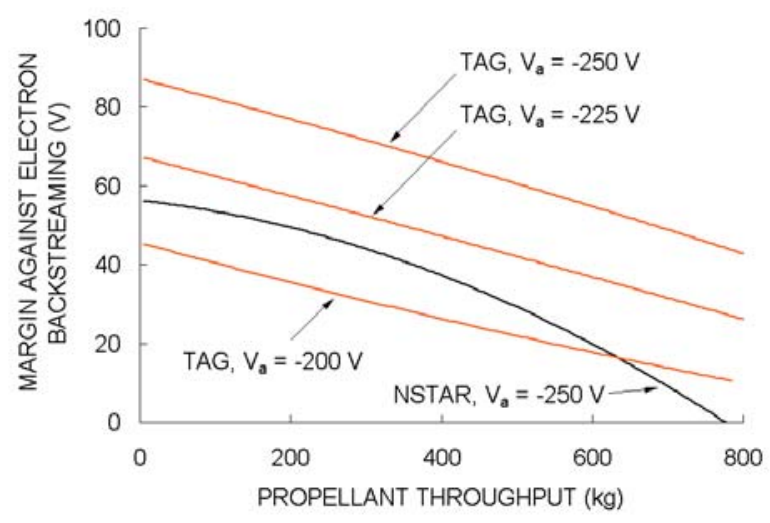

Fig. 8 Backstreaming margin of apertures operating at $\mathrm{J}_{\mathrm{B}}=3.52 \mathrm{~A}, \mathrm{~J}_{\mathrm{b}}=0.167 \mathrm{~mA}$, and $\mathrm{V}_{\mathrm{b}}=1800 \mathrm{~V}$.

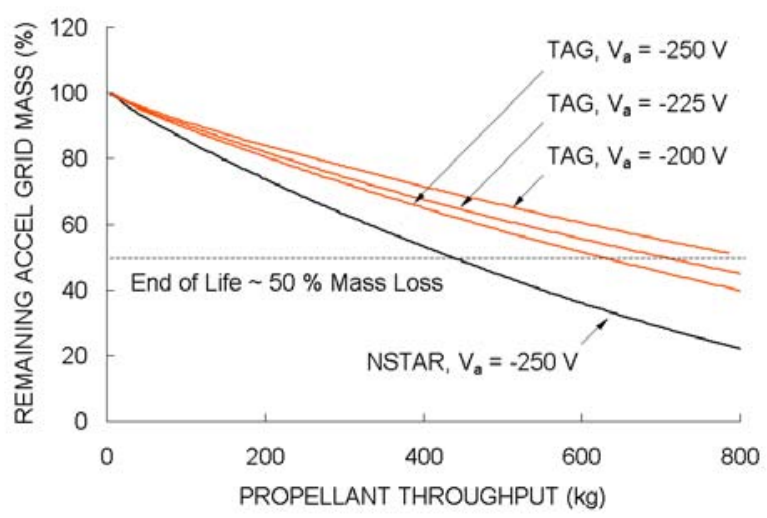

Fig. 9 Accel grid mass loss of apertures operating at $\mathrm{J}_{B}$ $=3.52 \mathrm{~A}, \mathrm{~J}_{\mathrm{b}}=0.167 \mathrm{~mA}$, and $\mathrm{V}_{\mathrm{b}}=1800 \mathrm{~V}$.

The erosion simulations performed at $3.52 \mathrm{~A}$ along with the information presented in Fig. 2 predict that the thruster centerline apertures will determine the end of life for both the NSTAR and TAG grids sets for all NEXT operating conditions. The centerline apertures receive more charge exchange ion current and are more likely to have electron backstreaming occur than apertures at larger radii.

Erosion simulations were performed at beam currents of 2.70 and 3.10 A over a range of net accelerating voltages to compare how apertures operating at identical beamlet currents eroded at different NEXT operating points. For the 2.70 A beam current condition, the peak beamlet current was $0.138 \mathrm{~mA}$ using a flatness parameter of 0.66 . For the $3.10 \mathrm{~A}$ beam current condition, the peak beamlet current was 0.153 $\mathrm{mA}$ using a flatness parameter of 0.68 . Also simulated at the $3.10 \mathrm{~A}$ beam current condition was a beamlet current of $0.168 \mathrm{~mA}$ in order to compare results from the ffx code to those obtained at the University of Michigan. ${ }^{5}$ The simulated beam voltages were 1800 , $1567,1396,1179$, and $1021 \mathrm{~V}$, with corresponding accel grid voltages of $-250,-225,-220,-200$, and -175 V. Normalized perveance per hole $\left(\mathrm{P}_{h}\right)$ is defined as

$$
\begin{aligned}
& P_{h}=\frac{\left(\frac{J_{b}}{A_{h}}\right) \frac{l_{e}{ }^{2}}{V_{T}^{3 / 2}}}{\frac{4 \varepsilon_{0}}{9} \sqrt{\frac{2 e}{m}}}, \text { where } A_{h}=\frac{\pi d_{s}^{2}}{4} \\
& \text { and } l_{e}=\sqrt{\left(t_{s}+l_{g}\right)^{2}+\frac{d_{s}^{2}}{4}} .
\end{aligned}
$$


Figure 10 shows the initial accel grid barrel erosion rate as a function of normalized perveance per hole for the 0.138 and $0.168 \mathrm{~mA}$ beamlet current conditions predicted by the ffx code. Here, the barrel erosion rates at both conditions increase as the perveance increases with the exception of the last points on both curves, which correspond to the smallest beam voltages tested at each beamlet current. Results from the University of Michigan at the $0.168 \mathrm{~mA}$ beamlet current condition suggested a maximum erosion rate of the aperture barrel at a normalized perveance per hole value of about $0.31 .^{5}$ A slight decrease in barrel erosion rate as normalized perveance per hole increased above 0.36 was seen in the ffx code results at the same condition. A decrease in the barrel erosion rate was also seen at the $0.138 \mathrm{~mA}$ beamlet current condition greater than a normalized perveance per hole value of about 0.37 .

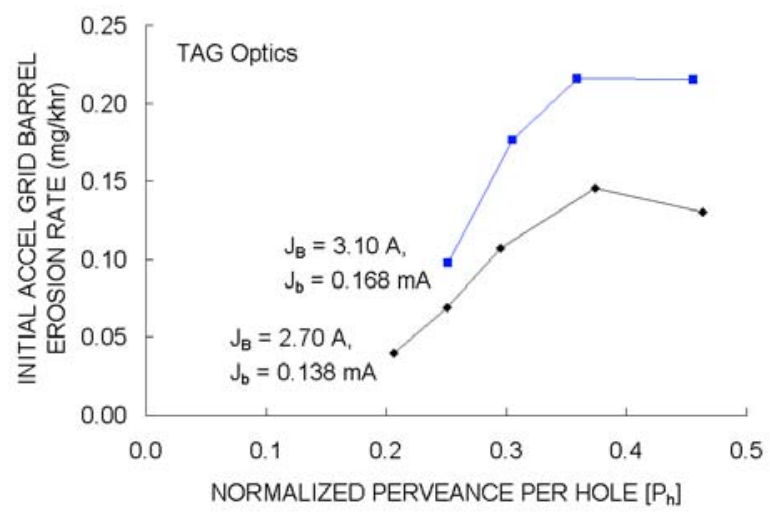

Fig. 10 Barrel erosion rates as a function of normalized perveance per hole.

Figure 11 compares the rates of charge exchange ion production in each cell and subsequent charge exchange ion termination surfaces for three beam voltages at the $0.138 \mathrm{~mA}$ beamlet current condition. These images are also indicative of the 0.153 and $0.168 \mathrm{~mA}$ beamlet current conditions over similar beam voltage ranges. At a beam voltage of $1021 \mathrm{~V}$, where the beamlet was operating closer to the perveance limit, more ions from the region between the grids were directed into the accel grid barrel than at a beam voltage of $1800 \mathrm{~V}$, where the beamlet was operating farther away from the perveance limit. Conversely, as perveance increases, both the beam and accel grid voltage magnitudes decrease and, as a result, charge exchange ions strike the accel grid with less energy. These two effects together support the trends in initial accel grid barrel erosion rate seen in Fig. $10 .^{5}$

Figure 12 compares the propellant throughput capability of the nine erosion cases operating at beamlet currents of 0.138 and $0.153 \mathrm{~mA}$ with varying beam and accel grid voltages. In each case, the end of life was determined by accel grid mass loss leading to structural failure rather than by electron backstreaming. The rates of accel grid mass loss were lowest at the highest perveance values, in spite of greater initial barrel erosion rates at higher perveance values seen in Fig. 10. This was presumably a result of the increased accel grid voltage magnitudes at greater beam voltages. All of the nine cases showed that nearly all of the accel grid mass loss occurred on the downstream face of the accel grid and not on the barrel. In the cases with higher normalized perveance per hole values, only the cusps were worn away on the accel grid barrels with no further widening of the apertures taking place. With nearly equal amounts of charge exchange ion current reaching the downstream face of the accel grid in each case, the accel grid with the greatest applied voltage magnitude would be expected to erode away the most rapidly because impacting charge exchange ion energies would be greater. 
Charge exchange ion termination surfaces.
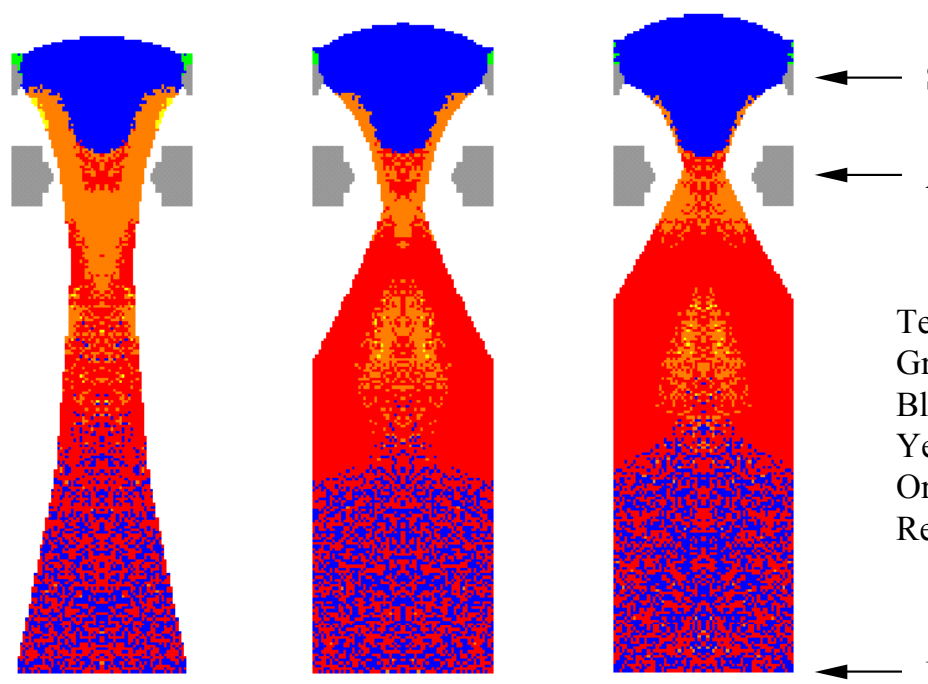

Screen Grid

Accel Grid

Termination Surfaces:

Green - screen grid

Blue - downstream boundary

Yellow - upstream side of accel grid Orange - accel grid barrel

Red - downstream side of accel grid

Downstream Boundary

Charge exchange ion production (scales are different in each).

$1.215 \cdot 10^{-11} \mathrm{~A} /$ cell

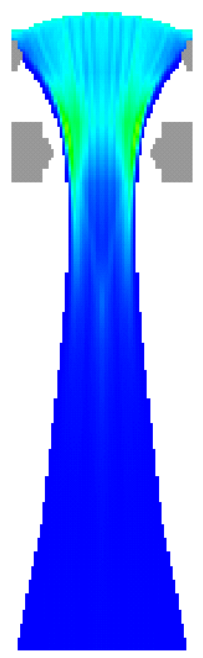

$$
\mathrm{V}_{\mathrm{b}}=1021 \mathrm{~V}
$$$$
\mathrm{V}_{\mathrm{a}}=-175 \mathrm{~V}
$$

$2.789 \cdot 10^{-11} \mathrm{~A} /$ cell

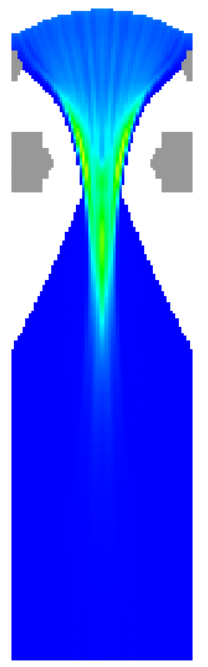

$$
\mathrm{V}_{\mathrm{b}}=1396 \mathrm{~V}
$$

$\mathrm{V}_{\mathrm{a}}=-220 \mathrm{~V}$
$5.423 \cdot 10^{-11} \mathrm{~A} /$ cell

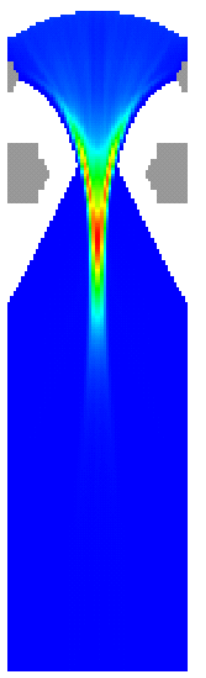

$\mathrm{V}_{\mathrm{b}}=1800 \mathrm{~V}$ (see left for maximum scale values)

$0.0 \mathrm{~A} /$ cell

Common Conditions:

TAG optics

$\mathrm{J}_{\mathrm{B}}=2.70 \mathrm{~A}$

$\mathrm{J}_{\mathrm{b}}=0.138 \mathrm{~mA}$

Fig. 11 Charge exchange ion information as a function of beam voltage. 


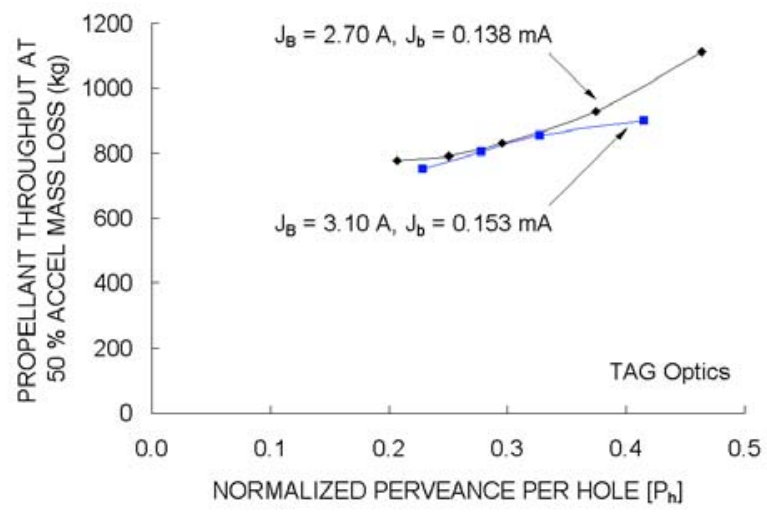

Fig. 12 Propellant throughput capability of thruster centerline apertures.

A summary of all lifetime calculations performed using the ffx code is presented in Table 2.

TABLE 2 Summary of ffx code lifetime predictions.

$\begin{array}{ccccccc}\text { Grid Set } & \mathrm{V}_{\mathrm{b}}(\mathrm{V}) & \mathrm{V}_{\mathrm{a}}(\mathrm{V}) & \mathrm{J}_{\mathrm{B}}(\mathrm{A}) & \mathrm{J}_{\mathrm{b}}(\mathrm{mA}) & \begin{array}{c}\text { Throughput at } \\ 50 \% \text { Accel } \\ \text { Mass Loss }(\mathrm{kg})\end{array} & \begin{array}{c}\text { Remaining Margin } \\ \text { Against Electron } \\ \text { Backstreaming }(\mathrm{V})\end{array} \\ \text { NSTAR } & 1800 & -250 & 3.52 & 0.167 & 435 & 34 \\ \text { TAG } & 1800 & -250 & 3.52 & 0.167 & 625 & 54 \\ \text { TAG } & 1800 & -225 & 3.52 & 0.167 & 700 & 32 \\ \text { TAG } & 1800 & -200 & 3.52 & 0.167 & 805 & 10 \\ & & & & & & \\ \text { NSTAR } & 1800 & -250 & 3.52 & 0.118 & 600 & 58 \\ \text { TAG } & 1800 & -250 & 3.52 & 0.118 & 945 & 80 \\ & & & & & & \\ \text { TAG } & 1800 & -250 & 3.1 & 0.153 & 750 & 59 \\ \text { TAG } & 1567 & -235 & 3.1 & 0.153 & 805 & 57 \\ \text { TAG } & 1396 & -220 & 3.1 & 0.153 & 855 & 56 \\ \text { TAG } & 1179 & -200 & 3.1 & 0.153 & 900 & 71 \\ & & & & & & 65 \\ \text { TAG } & 1800 & -250 & 2.7 & 0.138 & 780 & 65 \\ \text { TAG } & 1567 & -235 & 2.7 & 0.138 & 790 & 72 \\ \text { TAG } & 1396 & -220 & 2.7 & 0.138 & 830 & 61 \\ \text { TAG } & 1179 & -200 & 2.7 & 0.138 & 930 & 1115 \\ \text { TAG } & 1021 & -175 & 2.7 & 0.138 & & \end{array}$

\section{CONCLUSIONS}

Reasonable simulations of grid erosion for the two proposed sets of NEXT ion thruster grids were obtained using the ffx code. Structural failure of the accel grid due to excessive erosion of the downstream face, rather than the onset of electron backstreaming, was the predominant failure mode of both the NSTAR and TAG grid sets. The TAG grid set outperformed the NSTAR grid set both in terms of margin against electron backstreaming and accel grid mass loss at the $3.52 \mathrm{~A}$ beam current and $1800 \mathrm{~V}$ beam voltage condition. Additionally, increases in propellant throughput capability with decreases in accel grid voltage magnitude were seen for the TAG grid set at this same thruster operating condition. Erosion simulations were performed for the thruster centerline apertures at beam currents of 2.70 and $3.10 \mathrm{~A}$. The longest lifetimes were achieved at lower beam and accel grid voltages corresponding to higher perveance values.

\section{REFERENCES}

1 Patterson, M.J., Foster, J.E., Haag, T.W., Rawlin, V.K., Soulas, G.C., and Roman, R.F. "NEXT: NASA's Evolutionary Xenon Thruster." $38^{\text {th }}$ Joint Propulsion Conference, AIAA 2002-3832, Cleveland, OH, July 2002.

${ }^{2}$ Soulas, G.C. "Improving the Total Impulse Capability of the NSTAR Ion Thruster with Thick-AcceleratorGrid Ion Optics." $27^{\text {th }}$ International Electric Propulsion Conference, IEPC-01-081, Pasadena, CA, October 2001.

3 Soulas, G. C., Haag, T. W., and Patterson, M. J. "Performance Evaluation of $40 \mathrm{~cm}$ Ion Optics for the Next Ion Engine." $38^{\text {th }}$ Joint Propulsion Conference, AIAA-2002-3834, Cleveland, OH, July 2002.

4 Williams, J.D., Laufer, D.M., and Wilbur, P.J. "Experimental Performance Limits on High Specific Impulse Ion Optics," 28 ${ }^{\text {th }}$ International Electric Propulsion Conference, IEPC-03-128, Toulouse, France, March 2003.

5 Emhoff, J.W., Boyd, I.D., and Shepard, S.P. "Numerical Analysis of Next Ion Thruster Optics" $28^{\text {th }}$ International Electric Propulsion Conference, IEPC-03110, Toulouse, France, March 2003. 


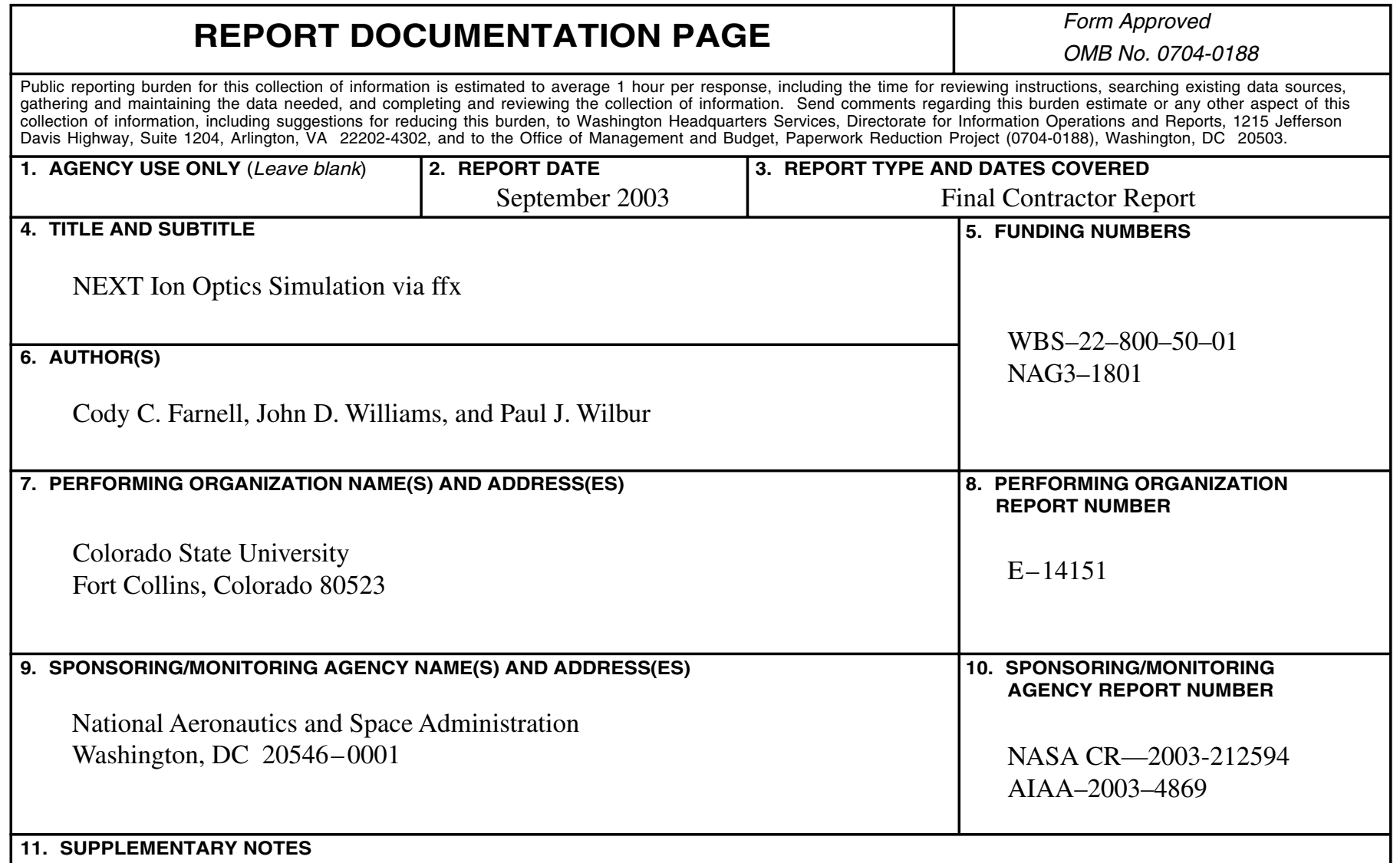

Prepared for the 39th Joint Propulsion Conference and Exhibit cosponsored by the AIAA, ASME, SAE, and ASEE, Huntsville, Alabama, July 20-23, 2003. Project Manager, George Soulas, Power and On-Board Propulsion Technology Division, NASA Glenn Research Center, organization code 5430, 216-977-7419.

12a. DISTRIBUTION/AVAILABILITY STATEMENT

12b. DISTRIBUTION CODE

Unclassified - Unlimited

Subject Category: 20

Distribution: Nonstandard

Available electronically at http://gltrs.grc.nasa.gov

This publication is available from the NASA Center for AeroSpace Information, 301-621-0390.

13. ABSTRACT (Maximum 200 words)

Simulations of the erosion processes for two proposed sets of ion thruster grids for the NEXT project are presented. Structural failure and electron backstreaming due to accelerator grid erosion are discussed as two possible failure mechanisms of these grid sets. The TAG grid set was seen to outperform the NSTAR grid set both in terms of margin against electron backstreaming and accelerator grid mass loss for a variety of operating points. An investigation into the possibility of reducing the accelerator grid voltage magnitude for the TAG grid set showed improved propellant throughput capability.

14. SUBJECT TERMS 15. NUMBER OF PAGES

Ion thruster; Ion engine; Ion propulsion 16

\begin{tabular}{|c|c|c|}
\hline $\begin{array}{c}\text { 17. SECURITY CLASSIFICATION } \\
\text { OF REPORT } \\
\text { Unclassified }\end{array}$ & $\begin{array}{c}\text { 18. SECURITY CLASSIFICATION } \\
\text { OF THIS PAGE } \\
\text { Unclassified }\end{array}$ & $\begin{array}{c}\text { 19. SECURITY CLASSIFICATION } \\
\text { OF ABSTRACT } \\
\text { Unclassified }\end{array}$ \\
\hline
\end{tabular}

NSN 7540-01-280-5500 